\title{
TRANSPARENCY IN FORCE MODERNIZATION DECISIONS
}

\author{
Robert K. MURPHY and G. Richard CATHERS
}

\begin{abstract}
Transparency, as defined for this paper, is the continual process of openness, accountability, and governance, plays a vital role in force modernization decisions. It is essential in capabilities-based planning (CBP), and because of rising acquisition costs, transformation has become the overall vision for military strategy. Transformation is implemented by capabilities-based planning resulting in force modernization decisions. Without a well defined, repeatable, and transparent evaluation process, national vulnerabilities and required capabilities might be incorrectly identified, resulting in wrong solutions. Force modernization decisions based upon transparency can provide the basis for a highly effective, low cost solution. The solution does not have to be a technical solution, but can be a change in Doctrine; Organization; Training; Leadership development; Materiel; Personnel; or Facilities (DOTLMPF). By including transparency for identifying requirements, we can ensure that the requirement answers the how, what, why, when, and who so that a credible decision can be made. Force modernization decisions using capabilities based planning and value tools that help structure and evaluate requirements have been used very effectively. A simple, top-down approach of Strategy to Need is used to initiate the evaluation. Force modernization decisions should be made using processes, methodologies, and supporting tools which allow for fully transparent assessments for the decision-maker. In other words, assessments should be traceable and accountable. Processes should be clear, methodologies should be simple, and the tools should be easy to use and understand. Several countries have successfully used this process for evaluating alternatives against a set of requirements. These assessments have included upgrading fleets, restructuring organizations, and acquiring new equipment.
\end{abstract}

Keywords: Transparency, force modernization, requirements, acquisition, strategy, transformation, capability, capabilities-based assessment

\section{Introduction}

The United States Department of Defense (DOD) describes transformation as "a process that shapes the changing nature of military competition and cooperation through new combinations of concepts, capabilities, people, and organizations that 
exploit our nation's advantages and protect against our asymmetric vulnerabilities to sustain our strategic position, which helps underpin peace and stability in the world." Force modernization planning (the natural process of improving equipment and training, etc. as time progresses) is one means of implementing the strategic vision of transformation within the military. Both force modernization planning and transformation imply that a capabilities based planning approach must be taken in order to successfully make acquisition decisions. Capability based planning that implements transformation should be made using processes, methodologies, and supporting tools that allow for fully transparent assessments for the decision maker. The results of the assessment should be understandable to the decision maker and the rationale and methodology that led to the result should be traceable. At a broad level, transparency ensures the following:

- Guidelines and rules for decision-making are established;

- The proper organization for implementing the modernization planning is in place;

- The best decisions are being made;

- The decisions are being made as quickly as possible.

Even when the mechanisms for transparency are in place, one of the main challenges is credibility; that is, how believable the decision is. One of the challenges in the military and government is that the overall credibility with sharing information and being forthright in acquisition decisions has suffered greatly. "In order to improve our overall credibility, we are going the extra mile in trying to be more open and engaging, more proactive, and preemptive in how we do acquisition business, "2 said Kenneth Miller, special assistant to the secretary of the Air Force for acquisition governance and transparency. That means openness, accountability, and governance. In the end, successful transformation and force modernization of military forces can not occur without transparency and transparency can not occur without the proper organizations, guidelines, methods, and tools to implement it.

\section{Transparency Defined}

\section{Openness, Accountability, and Governance}

Transparency shown in Figure 1 is an iterative process that ensures credibility through openness, accountability, and governance. Openness involves a two-way communication that is used for information flow and generating ideas. Accountability is the obligation or willingness to take responsibility. Governance is that separate part of transparency that makes decisions, defines expectations, and verifies performance. Frequently a committee or some other governance body is established to administer 


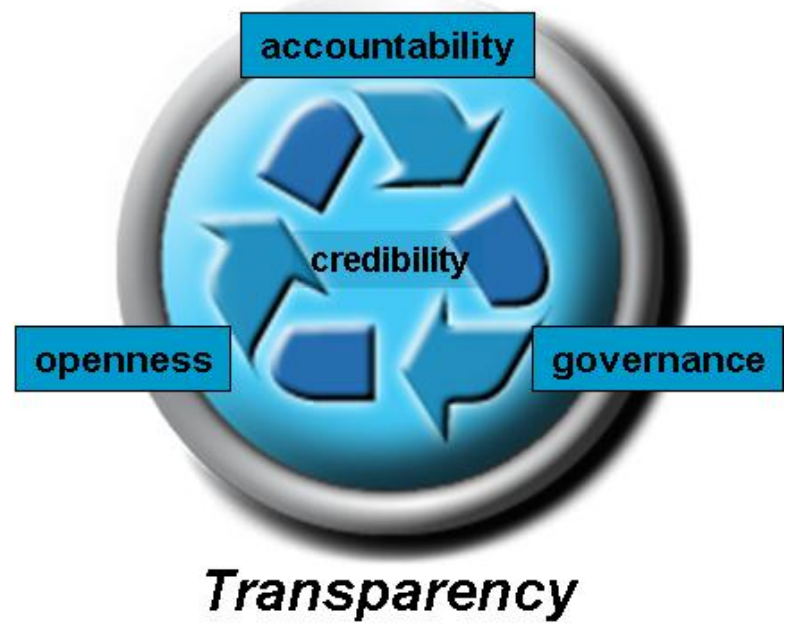

Figure 1: Transparency Process.

these processes and systems. It is a continuous cycle of checks and balances leading to a credible solution.

Governance can be defined as the collection of mechanisms that allows the organization to make the best decisions as fast as possible. Standards, training, role descriptions, process guidelines, and requirements documents are examples of governance mechanisms. "Governance means that you want to create an appropriately sized organization that can provide oversight, develop procedures, and enforce rules - the scope and "jurisdiction." ${ }^{3}$ This could be the whole company, one project, or a small group.

By properly implementing governance (and of course openness and accountability) the best decisions possible can be made and they can be made as fast as possible.

Governance should create a "greater good" that helps achieve goals and solves real problems that are clearly defined before you decide to implement governance in the first place. Also, decisions that are made should be put to use with minimal delay. One needs to keep in mind the tradeoffs between a "quick but bad decision that will haunt you later" and by "analysis paralysis." Don't forget that these decisions will benefit some and not others. And those it will hurt may try to spoil the entire process. ${ }^{4}$

Therefore, capabilities-based planning needs transparency in every aspect of the force modernization process. This is especially true in the early stages when requirements are being defined and evaluated prior to an acquisition decision. 
In addition to governance, the amount of oversight that is required remains a big issue. One of the big challenges for DOD and Congress is the right degree of oversight and review you have in the future, especially on ethics, people and standards and how they approach disclosure. Mr. Miller said. "I don't think you will ever get away from where your people make mistakes ... (but) what is important is that you have an adequate set of processes in place to recognize them." You also need to strike a balance in governance. Unnecessary administration and oversight inhibit decision making.

\section{Transparency's Role in Capabilities-Based Planning}

Transparency plays a critical role in capabilities-based planning by ensuring governance, openness, and accountability. But what does transparency have to do with making the actual force modernization planning decisions? The Guide to CapabilityBased Planning ${ }^{6}$ states:

"CBP provides a more rational basis for making decisions on future acquisitions, and makes planning more responsive to uncertainty, economic constraints, and risk." The goals of designing the CBP should include the following:

- Determine who will do what work (effectiveness analysis, cost-benefit analysis, and tradeoff studies within and among capabilities);

- Determine who has the responsibility for the outcomes (approval and coordination);

- Determine the resources required (for analysis, as well as R\&D);

- Determine how long a planning cycle will take;

- Determine what the outcome or outcomes of the process will be;

- Determine the products to be produced;

- Ensure the process meets the constraints such as timeliness.

This is important, especially given the number of acquisition decisions that must be made, and the amount of potential effort placed on each acquisition decision. As an example of this, the United States Quadrennial Defense Review ${ }^{7}$ established in 1996, followed this process. As stated by the Heritage Foundation ${ }^{8}$ :

What the QDR accomplished, unlike previous Cold War strategic assessments [threat based assessments], was to add some transparency to the process and offer a routine platform for dialogue between Congress and the Administration. Creating an iterative process is the greatest virtue of the QDR. Periodic reviews offer two advantages:

- They encourage the armed forces to think deeply about how to match strategy, requirements, and resources; justify their judgments; and institutionalize the capability to make these assessments.

- They provide an audit trail for congressional and other government leaders to assess long-term defense trends.

Most important, the QDR provides a means for government to conduct and Congress to consider strategic assessments in a disciplined and systematic manner. 
The QDR, as defined by transparency, had a clear and understandable process required to understand the complex world of defense planning and acquisition.

\section{Capability-Based Planning and Transparency - A Top-Down Approach}

It is very important that early on in the decision making process everyone understand the requirements generation approach. It is not enough to know the physical characteristics of an acquisition in order to determine what equipment is required. You must have a compelling need for the acquisition, and you must be able to measure its value against some set of requirements versus other alternatives. In other words, requirements should be defined with a clear picture of what they will be used for.

\section{Capabilities-Based Planning Requirements}

So, instead of asking one question: "What do we need to replace existing equipment?" we need to ask several questions.

- What - What are the known elements, functions, and gaps of the capability?

- Where - Where will the capability be used? What are the geographical and physical boundaries of the system?

- When - When will the capability be needed?

- How - How will the capability accomplish the operation? What resources do we need to design, build, or maintain the system?

- Who - Who are the stakeholders involved?

- Why - Why do we need it? What is the compelling need?

In order to properly answer these questions, mission analyses have to be performed, which put all potential requirements in context with the questions that are being asked. The question being asked should pertain to the national security strategy of the country in question. For example, the National Security Strategy of the United States of America includes the following strategic guidance:

- Champion aspirations for human dignity;

- Strengthen alliances to defeat global terrorism and work to prevent attacks against us and our friends;

- Work with others to defuse regional conflicts;

- Prevent our enemies from threatening us, our allies, and our friends, with weapons of mass destruction;

- Ignite a new era of global economic growth through free markets and free trade;

- Expand the circle of development by opening societies and building the infrastructure of democracy;

- Develop agendas for cooperative action with other main centers of global power; 
- Transform America's national security institutions to meet the challenges and opportunities of the twenty-first century.

The strategic guidance was based on the current environment as viewed by President George W. Bush:

“...Defending our Nation against its enemies is the first and fundamental commitment of the Federal Government. Today, that task has changed dramatically. Enemies in the past needed great armies and great industrial capabilities to endanger America. Now, shadowy networks of individuals can bring great chaos and suffering to our shores for less than it costs to purchase a single tank. Terrorists are organized to penetrate open societies and to turn the power of modern technologies against us."

Once a compelling need has been identified, concepts of how to accomplish the strategy or how a force plans to operate can be defined. For example, a strategy of deterring threats as shown in Figure 2 might have a concept of denying enemy sanctuary and projecting and sustaining forces. The operational concept can be decomposed into concept of operations (tasking) or by identifying specific intents or aims. For example, a commander in the field might interpret protecting critical bases as performing an air to ground mission.

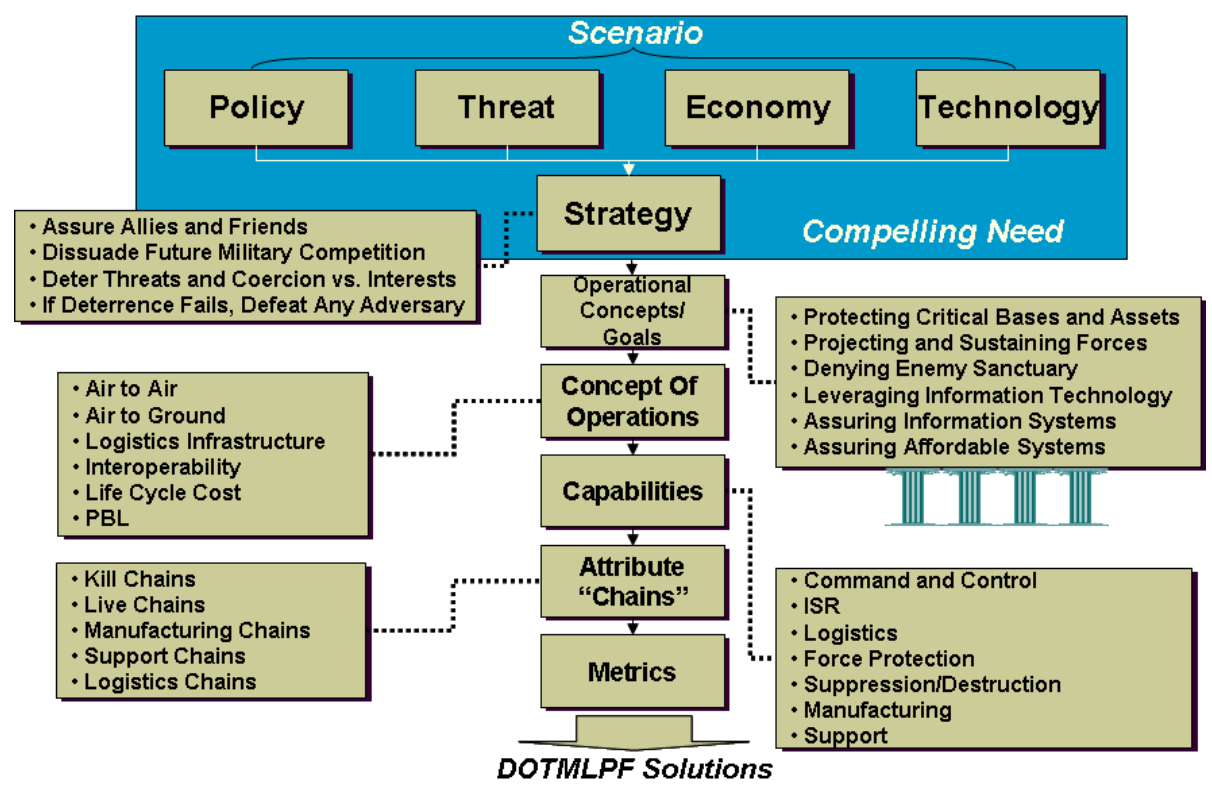

Figure 2: Defining the Requirements Hierarchy. 


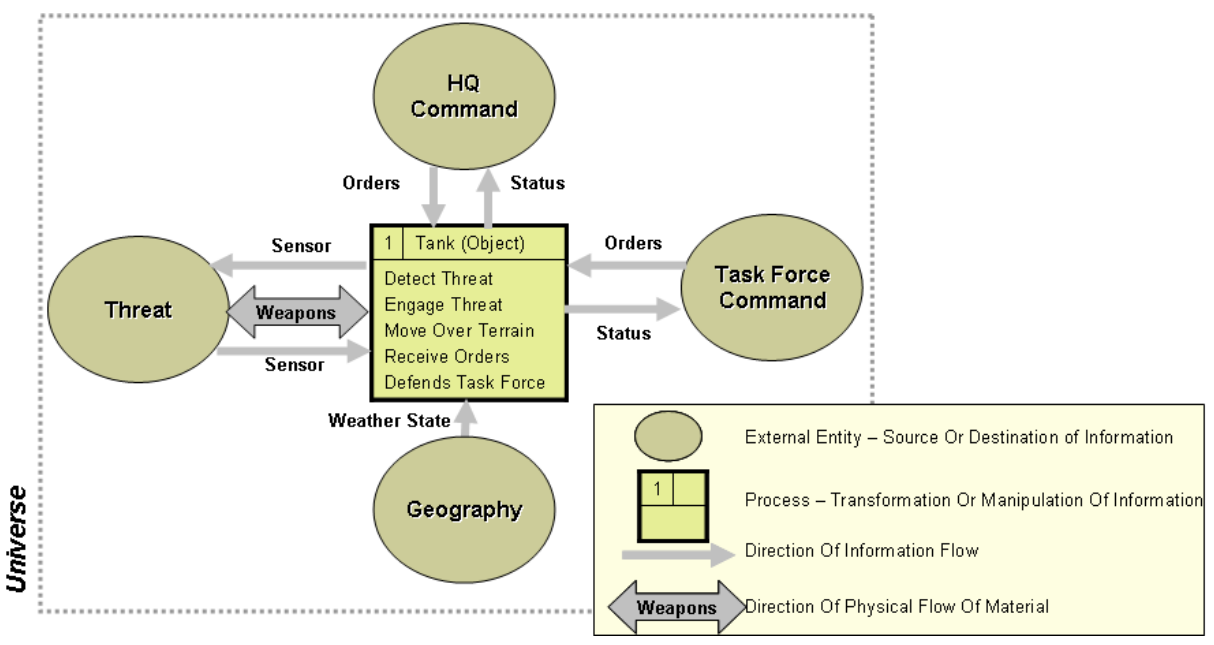

Figure 3: Defining Attributes Using Context Diagrams.

So, based on future scenarios that include threat assessments, trends in technology and economics, or changes in policy, and strategic guidance at the national level, a compelling need can be identified. All of this information provides contextual information and constraints in order to establish how we will accomplish our objective. In other words, context and constraint information will answer what, where, and when. This, combined with the strategic guidance will answer why. Finally, the stakeholders (or who) provide the ground rules and assumptions, and other required information needed to make a successful decision.

\section{Scenario and Strategy Development}

Scenario development is undoubtedly one of the most important aspects of capabilitybased planning, yet it is frequently ignored. Scenarios provide the overall context for planning. They can also be used to present alternative futures. By using several scenarios, solutions can be evaluated against several possibilities. The idea is to build a robust and agile force that can address as many contingencies as possible. Scenarios are built by looking at trends in technology, changes in threat, vulnerabilities, political stability, or economics. Scenarios also rely on National Policies which help bound the scenario.

Although scenarios are essential to capability-based planning and provide context, they still do not provide all of the information required to develop a strategy. A vision or story must be created and agreed upon by planners. A vision is a concentrated set of goals with agreed upon expectations. It is a way of shaping the future by using 
probable scenarios and is a basis for determining strategy. In the end, strategy is the response to the vision.

\section{Context Diagrams}

Once strategies and concepts have been defined, the work of identifying capabilities and capability gaps can begin. Capabilities use relevant parameters and associated metrics to quantify the key attributes of forces in order to determine how capable they are of performing those critical tasks needed to accomplish future military objectives. Stated simply, capabilities are identified based on the required tasks. To illustrate this, we can use a context diagram to represent the environment and boundaries of a specified concept as shown in Figure 3.

A context diagram (or any architectural diagram) is a means of describing a system that everybody agrees on and forces people to explain their assumptions. It helps clarify the story and key questions. The interfaces in the diagram help you understand the way the elements in the system are reinforcing or balancing one another.

Let's assume we have an operational concept of protecting ground units under a strategy of "defending the border." From this we can determine specific tasks such as perform mechanized ground combat. Once the tasks have been defined, we can determine what capabilities are needed to accomplish the task. One capability might be the ability to protect a tank.

\section{Attribute Chains}

Each capability can then be decomposed into a set of attributes or characteristics. For example, the capability of protecting a tank might be described as sending and receiving orders, delivering a weapon, and moving. These attributes can be aggregated into sets such as internal or external, lethality or survivability. These are the necessary and sufficient characteristics needed to define a capability. For our purposes, these have been defined as "attribute chains" - so called because each link in the chain is an implied necessary characteristic, while the set of links is sufficient. For example, air combat lethality, as illustrated in Figure 4, could be described using a kill chain \{Acquire, Identify, Build Firing Solution, Deliver Weapons, Conduct Bomb Damage Indication $\}$.

The lethality kill chain can be thought of as five links in a chain whereby each link in the chain must be accomplished, in sequence, in order to kill the intended target. If any of the first four links are broken the attack will not succeed. Successful completion of the final link, "Conduct Bomb Damage Indication (BDI)" allows for more efficient operations and eliminates unnecessary subsequent attacks on the target. 


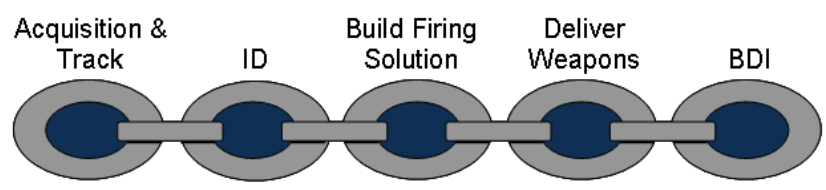

Lethality Kill Chain

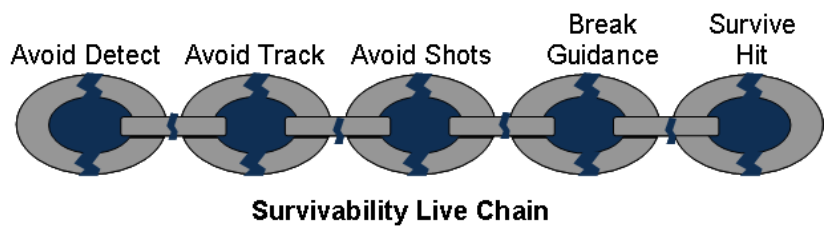

Figure 4: Lethality Kill Chain and Survivability Kill Chain.

The survivability live chain can also be thought of as five links in a chain whereby one must break any link in the chain in order to help ensure survival in a threat encounter. The earlier the link is broken, the higher the probability of mission survival and success is realized.

Finally, each of the characteristics needs to be measurable. A measurement of "acquire" might be range in nautical miles. Note that several measurements can be used to define a characteristic.

The final product from this process is a mission statement or requirements document that addresses the previous questions of what, when, where, how, who, and why. In other words, it is a statement that identifies a necessary attribute, capability, characteristic, or quality of a system in order for it to have value and utility to a user.

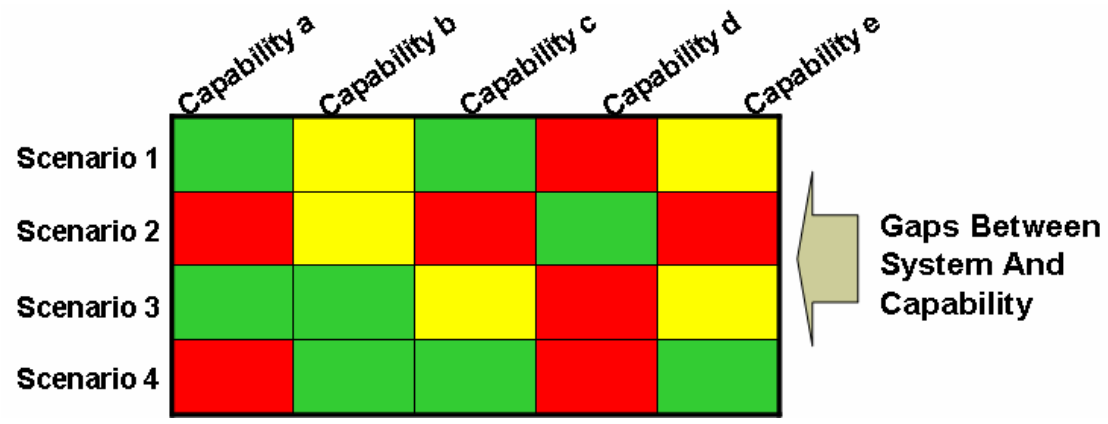

Figure 5: Capability Gaps. 


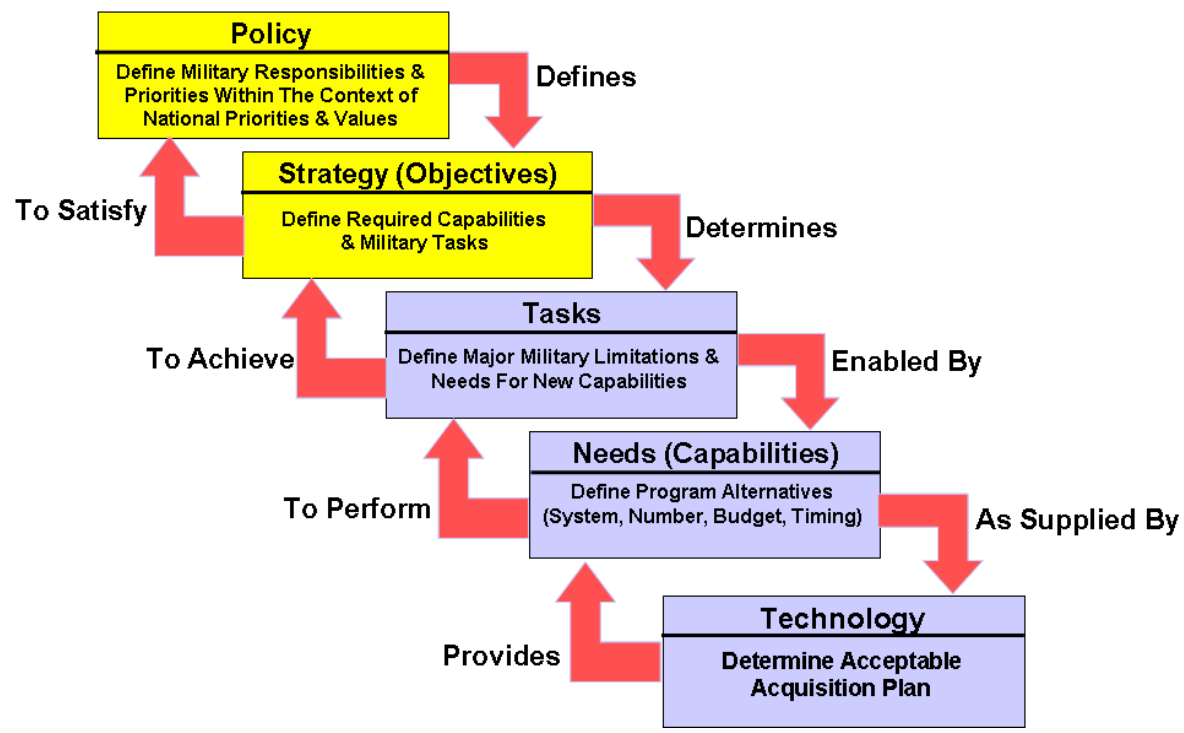

Figure 6: Strategies to Task to Need to Technology.

\section{Identifying Gaps}

Once capabilities have been identified, an assessment must be made to determine if any shortfalls or excess capability exist. This assessment is usually performed with a team of experts identified when the project was started. The assessment can be subjective or can be based on actual data or simulations. A matrix design illustrated in Figure 5 shows an assessment where each capability is always in context to the specified scenario. The aim of the assessment is to identify potential solutions to fill or reduce gaps in capability. The solution should address DOTMPLF. This means that not all solutions will involve an acquisition. The solution may suggest a change in doctrine or perhaps training.

\section{Strategy to Need}

Once these basic questions have been answered in developing requirements, a final check will determine if this is really what we want. In the end we will have a Strategy-to-Task-to-Need-to-Technology process as shown in Figure 6 that ensures we answer our question of compelling need.

For example, Environmental Factors influence National Policies which in turn help define the strategy. A strategy will determine required tasks, but it is the capabilities that enable the tasks. In turn, it is the technology (or non material solution) that actually meets the capability. We must then make sure that the technology provides the 
capabilities to perform tasks which will achieve your ultimate strategic objectives. If all of these steps are satisfied, a transparent assessment will satisfy the policies established by a country.

\section{Determining Value}

Assuming up to this point we have been following our capability-based planning process (transparency), requirements will have been identified and agreed on. We will also have identified and agreed to possible solutions: both materiel and nonmateriel. So, how do you determine which solution has the most value? Two elements of value must be considered. The first element is utility. The second element is cost. Utility is the perceived usefulness of a capability and is a unitless measure. This is shown in Figure 7 below.

The utility can be weighted, if desired, to show importance within a level of aggregation. Cost is simply the monetary measure of the solution.

To ensure that the possible solutions are evaluated properly and the results are credible, it is absolutely necessary to involve all subject matter experts in the acquisition planning process. Experts have the skills and knowledge required to provide credible inputs. This can be from practical experience or from observation, and it helps facilitate decision making. It is also critical to have an independent review team (as defined by governance) evaluate the proposed solutions.

The following approach demonstrates how we can determine value among a set of possible material solutions. Remember, if objectives are unrealistically optimistic or are not measurable, the program may not be able to demonstrate that it has been suc-

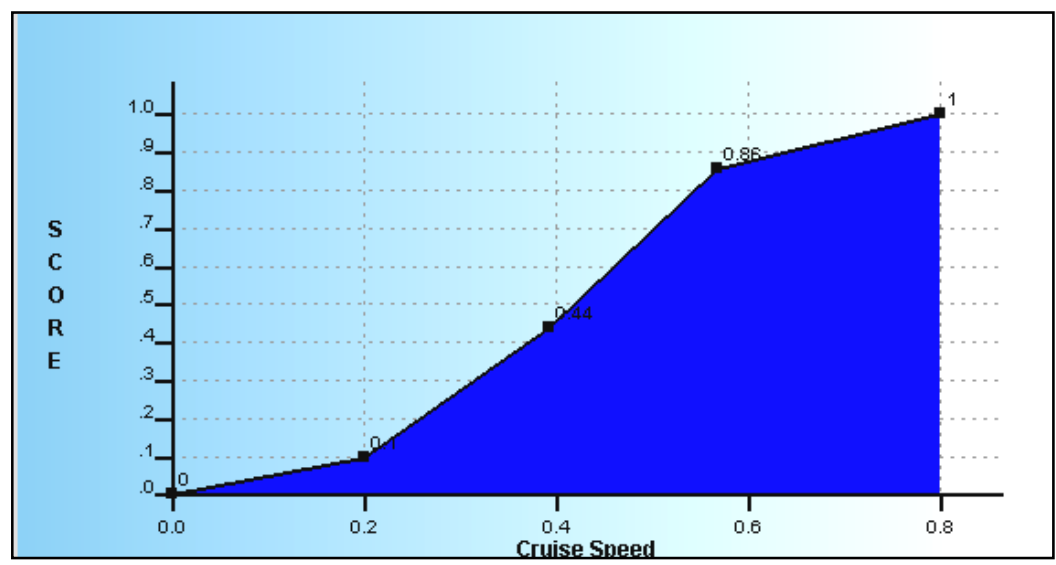

Figure 7: Utility Curve. 


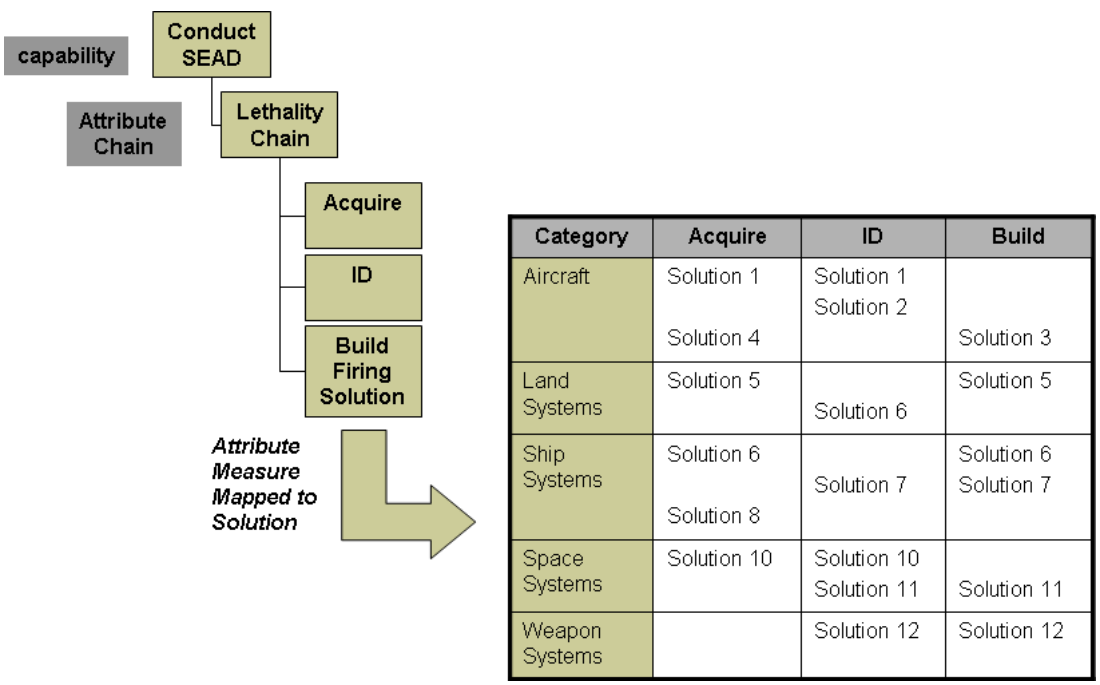

Figure 8: Mapping Requirements to Systems.

cessful even if it has done a good job developing or selecting from among alternative program approaches. Once requirements have been established, they can be mapped to different proposed solutions or alternatives as shown in Figure 8. The whole purpose of mapping is to establish possible alternatives (whether they are technical or non-technical) that meet the established requirements.

\begin{tabular}{|c|c|c|c|}
\hline Category & Acquire & ID & Build \\
\hline Aircraft & $\begin{array}{l}\text { Solution } 1 \\
\text { Solution } 4\end{array}$ & $\begin{array}{l}\text { Solution } 1 \\
\text { Solution } 2\end{array}$ & Solution 3 \\
\hline $\begin{array}{l}\text { Land } \\
\text { Systems }\end{array}$ & Solution 5 & Solution 6 & Solution 5 \\
\hline $\begin{array}{l}\text { Ship } \\
\text { Systems }\end{array}$ & $\begin{array}{l}\text { Solution } 6 \\
\text { Solution } 8\end{array}$ & Solution 7 & $\begin{array}{l}\text { Solution } 6 \\
\text { Solution } 7\end{array}$ \\
\hline $\begin{array}{l}\text { Space } \\
\text { Systems }\end{array}$ & Solution 10 & $\begin{array}{l}\text { Solution } 10 \\
\text { Solution } 11\end{array}$ & Solution 11 \\
\hline $\begin{array}{l}\text { Weapon } \\
\text { Systems }\end{array}$ & & Solution 12 & Solution 12 \\
\hline
\end{tabular}

Need Parameters And Metrics (MOPs, MOEs)

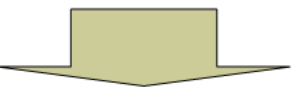

\section{These Can Be Weighted Using Judgment Or By Using Analytical Techniques}

\begin{tabular}{|l|l|l|l|}
\hline Acquire & Range & Speed & Payload \\
\hline Solution 1 & $600 \mathrm{NM}$ & 480 Knots & $2000 \mathrm{lbs}$ \\
\hline Solution 2 & $900 \mathrm{NM}$ & 400 Knots & $1000 \mathrm{lbs}$ \\
\hline Solution 3 & $500 \mathrm{NM}$ & 350 Knots & $3000 \mathrm{lb}$ \\
\hline
\end{tabular}

Figure 9: Determine the Metrics to Use to Measure Requirements. 


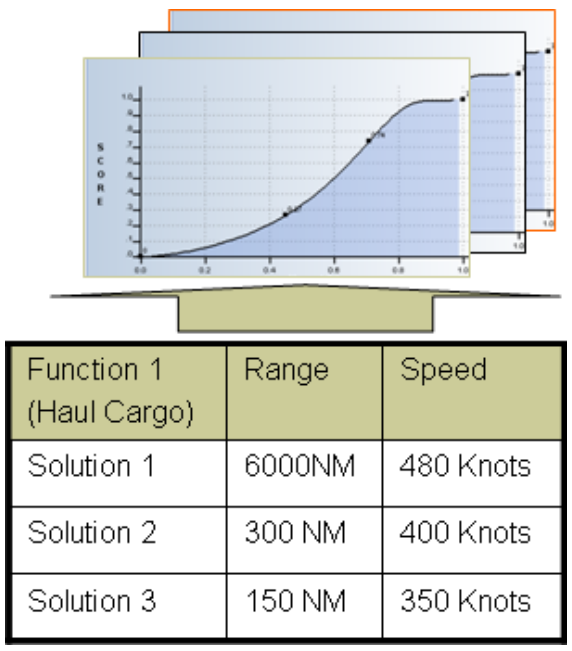

Figure 10: Utility Curves Used to Evaluate Solutions against Requirements.

In this illustration, solutions have been categorized into different platform systems. In addition, each feasible solution has been mapped to the appropriate attribute.

After the requirements are mapped to the alternatives, we need to determine measures of performance (MOP) and measures of effectiveness (MOE) so they can be evaluated. The metrics shown in Figure 9 need to be in context with the requirements. For example, range might differ depending on mission type and payload. Speed may vary depending on mission profile.

The next step is to establish utility or performance curves (Figure 10). These types of curves can be difficult to establish, especially when the effects are dependent on several variables. However, in many cases (especially qualitative metrics), subject matter experts can decide on how the curve should be shaped. That is, they can determine the utility of a metric.

When the requirements and curves are developed the alternatives can be evaluated based on their actual measures of performance. Figure 11 shows the simple calculation that takes place. It is the weight of the requirement times the score for the alternative. This calculation is then performed for all metrics and rolled up to a final value. One of the main challenges of determining value is the synergistic effects of capabilities and of the solutions themselves. For example, what is the added value of stealth on ISR? Or what is the added value of using aircraft in conjunction with sea power? 


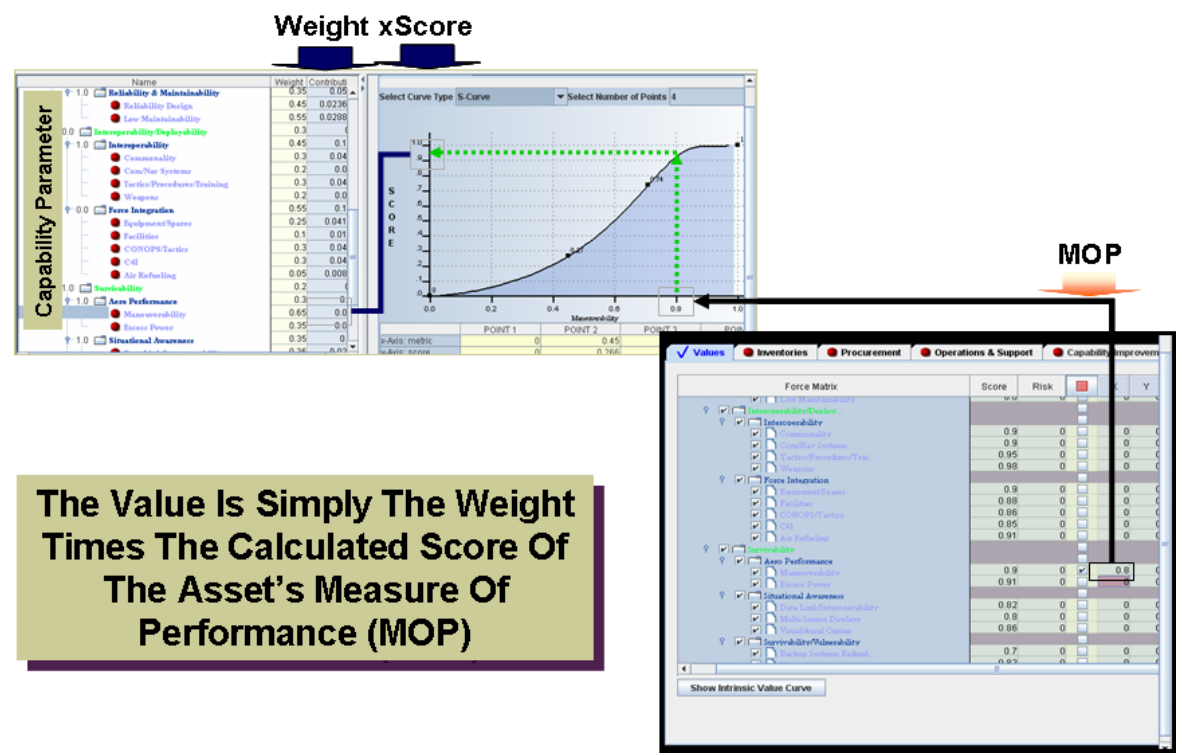

Figure 11: Final Scoring.

\section{Estimating Costs for Solutions}

Estimating costs for potential solutions is a very difficult yet necessary task in evaluating the cost-effectiveness of a solution. Costs should include the full life cycle cost of the solution. This includes investment, procurement of resources, maintenance, and if applicable, disposal. Since cost is probably the most visible aspect of capability based assessment, it is absolutely essential that there be clear and concise rules concerning ground rules and assumption, independent reviews, traceability, and audibility.

\section{Software Tools Used to Support Transparency in Force Modernization Decisions}

Because of the complexity of capability-based assessments and acquisition planning, software tools are generally used to structure the problem and evaluate it. In order to determine the value of a capability, methods such as Analytical Hierarchy Process or Utility Theory can be used. Several commercial models exist such as Expert Choice ${ }^{\circledR}$ which uses AHP. Another tool called Force Matrix Model (FMM) developed by Lockheed Martin uses AHP and Utility Theory to determine value. Both tools and methods ensure that transparency is incorporated, since neither method uses any factors or "black box" calculations. 


\section{Conclusion}

Evaluations of alternative systems for force modernization should allow for full flexibility in defining specific requirements, determining the importance of meeting those requirements and evaluating the capability of those alternative systems to meet those user-defined requirements. Methodologies and tools used to assist the decision-maker in modernization assessments should have adequate transparency for the decisionmaker to see the detailed evaluation parameters that were used in defining the requirements as well as assessing capabilities to meet those requirements.

An important element of the modernization evaluation process is to determine the level of detail when defining the requirements metrics. As the user decomposes the requirements the individual national and military strategies, tasks and resultant needs should provide the framework to decide the required detail.

Determining what level of expertise is required is another key aspect of setting up a modernization assessment process. The specific level of expertise will, in large part is driven by the level of detail required in defining the requirements and in the followon evaluation. The source of the various expertise needed is another challenge to the modernization assessment team. The subject matter experts may not be co-located with the assessment team which presents an additional challenge.

As the modernization assessment team progresses in defining overall requirements metrics, there may be certain requirements that will be overlapping or in some cases, conflicting. This challenge might be addressed by the proper selection of the decomposition elements that define the requirements and the weighting of those requirements.

Force modernization evaluations will contain risk and uncertainty in practically any evaluation that addresses the availability of new systems to meet future requirements. The degrees of risk can be addressed at the requirements level or at the scenario level where the evaluation results are totaled. Additionally, risk could have its own path during requirements decomposition to provide additional insight into the impact of various degrees of risk as it is altered parametrically using sensitivity analysis.

Interaction with multiple international partners has expanded to address a variety of modernization approaches such as upgrades, service life extension programs, new platform acquisitions and interim lease alternatives. This interaction has led to the acceptance by several different users who have applied this process to a variety of modernization approaches. This interaction has also led to the development of an informal user community to develop and define new requirements and methodologies that are shared with the entire user organization. 


\section{Bibliography}

Director, Office of Force Transformation, Elements of Defense Transformation (Washington, DC 20301-1000: Office of the Secretary of Defense, 1000 Defense Pentagon), www.oft.osd.mil, Date of Publication: October 2004.

The National Security Strategy of the United States of America (September 2002).

Mats Lindgren and Hans Banhold, Scenario Planning: The Link between Future and Strategy (Palgrave MacMillan Press, 2003).

Bryan D. Edmunds, Captain, USAF, Project Portfolio Management: An Investigation of One Air Force Product Center (Air Force Institute of Technology, March 2005).

Department of Defense Directive 5000.2, 12 May 2003, Joint Capabilities Integration and Development System, CJCS i3170.01e distribution: a, b, c, j, s, 11 May 2005.

Paul K. Davis, Analytic Architecture for Capabilities-Based Planning, Mission-System Analysis, and Transformation, Prepared for the Office of the Secretary of Defense, National Defense Research Institute (RAND Corporation, June 2002).

Guide to Capability-Based Planning, The Technical Cooperation Program, Joint Systems and Analysis Group, Technical Panel 3.

\section{Notes:}

1 Director, Office of Force Transformation, Office of the Secretary of Defense, "Elements of Defense Transformation," October 2004:2,<http://www.oft.osd.mil/library/library_files/ document_383_ElementsOfTransformation_LR.pdf >, (1 June 2007).

2 Staff Sgt. C. Todd Lopez, "Air Force Looks to Be Best in Acquisition," Air Force Print News, 12 January 2006, <http://www.af.mil/news/story.asp?storyID=123014083> (15 April 2007).

3 Jim Hertzfeld, "Simple Definition: Governance," 11 September 2006, <http://blogs.ittoolbox.com/pm/hertzfeld/archives/simple-definition-governance-11569> (15 April 2007).

${ }^{4}$ Hertztfeld, Simple Definition: Governance.

5 Todd Lopez, "Air Force Looks to Be Best in Acquisition." 
6 The Technical Cooperation Program, Joint Systems and Analysis Group, Technical Panel 3, "Guide to Capability-Based Planning," page 5, <www.dtic.mil/ttcp/JSA-TP-3-CBP-PaperFinal.doc> (May 2007).

7 Established in 1996, the Quadrennial Defense Review (QDR) requires the Pentagon every four years to provide to Congress a comprehensive assessment of defense strategy and force structure; program and policies; and modernization, infrastructure, and budget plans - outlining future requirements for the following eight years. The QDR has become a touchstone in the debates about restructuring the military and identifying the capabilities that will be needed for the new national security environment of the $21^{\text {st }}$ century. This effort offers lessons for considering how to establish a similar strategic review process for homeland security.

8 James Jay Carafano, Ph.D., "Thinking for the Long War: Strategic Planning and Review for the Department of Homeland Security," Heritage Lecture \#1008, <http://www.heritage.org/ Research/HomelandSecurity/tst032107a.cfm>, 28 March 2007 (10 June 2007).

9 The National Security Strategy of the United States of America (September 2002).

ROBERT K. MURPHY is a Manager for the Strategic Studies Group, Strategic Planning at Lockheed Martin Aeronautics Company. He has worked at Lockheed Martin Aeronautics Company for 19 years and is responsible for modeling and analysis in Economics, Force Structures Assessments, and Capability Based Assessments. Prior experience includes 3 years at Honeywell working on life cycle cost modeling of naval torpedo programs. He holds a Bachelor of Mathematics degree from the University of Minnesota, Institute of Technology and a Bachelor of Arts in German from the University of Minnesota, College of Liberal Arts. $\mathrm{He}$ also holds a Masters of Science in Operations Research from Southern Methodist University. E-mail: bob.k.murphy@lmco.com.

G. RICHARD CATHERS is a Senior Manager for the Strategic Studies Group, Strategic Planning at Lockheed Martin Aeronautics Company. He has been with Lockheed Martin for 18 years and is responsible for leading force structure assessments in support of Headquarters, United States Air Force and multiple international customers of Lockheed Martin. Prior experience includes 22 years in the U. S. Air Force in tactical fighter operations, force planning and international security policy for the Under Secretary of Defense for Policy in the Office of The Secretary of Defense. He holds a Bachelor of Science degree in Geology from Syracuse University and a Masters in Business Administration from Renssalaer Polytechnic Institute.E-mail: dick.cathers@1mco.com. 